\title{
An Empirical Assessment on the Relations Between the Euro Exchange Rate, Trade Balance and the Consumer Price Index: Case of Albania
}

\author{
Dr. Ilir Hoti \\ Dean of Economic Faculty- University "Alexander Moisiu", \\ Durres Albania (AU Tirana) \\ E-mail: ilirhoti@yahoo.com \\ MsC.Fiqiri Baholli \\ Professor in the Faculty of Economy and Agribusiness (AU Tirana) \\ E-mail: fbaholli@yahoo.com \\ Doc. Ines Dika \\ Professor in the Faculty of Economy and Agribusiness (AU Tirana) \\ E-mail: ines.dika@virgilio.it
}

\section{Doi:10.5901/mjss.2013.v4n10p541}

\section{Abstract}

As economic theory postulates, there are some relashionships between currency exchange rates, Consumer Price Index and External Trade Balance.. Normally, as exchange rates for the national currency go up, imports are supposed to go up as well, whereas exports are expected to go down. The opposite happens with a devaluating national currency. Additionally, Consumer Price Index is expected to go up with more expensive euros or dollars against ALL. More imports, particularly imports with higher prices, mean higher consumer prices, in a country relaying heavily on imports. We undertake this study to empirically and statististically estimate these relationaships, as far as there are no models used from Albanian institutions that deal with macroeconomic issues or forecasts. If these estimates confirm theory, this may mean that the economic principles, free and fair competition in particular, are working properly in Albania. In addition, we attempt to know how strong is correlation betewen these variables. Further on, we try to make short term forecasts for the echange rates of euro. The indicators used in our model are predicting the trends and relations among exchange rate, CPI and trade balance, although the data series are limited.

\section{Problem}

The economic theory tells us that the exchange rate between the national currency and exports or imports, therefore the trade balance, has a connection: the depreciation of the national currency (ALL) versus foreign currencies (ex. Euro (EUR) as the main foreign currency in the Albanian economy), and this evaluation, makes the imported goods to rise in the domestic market price) so it is expected an increase of the Consumer Price Index, CPI) and exported goods are sold cheaper in foreign markets. This promotes exports at a time when the goods are exported to overseas market competitive by improving the country's trade balance. On the other hand if the national currency is overevaluated, the effect is the opposite. Thus, the exchange rate becomes effective regulatory mechanism in international trade competition between different countries. This is more pronounced among countries with a relatively important position in international trade (let us remember the impact of the fluctuation of currency exchange rate between the Chinese economy and that of the U.S. in trade balance between the two countries. Obviously this strong connection is expected to occur at a time when competition is perefect and variables are measured without any error (this usually expresses the trade volume and exchange rate that exists in the market). On the other hand, in terms of low weight still Albanian exports the weak competition in international market fluctuations in exchange rates between our currency and EUR ALL$\mathrm{s}$ will affect not with the same intensity the fluctuation in consumer prices and the trade balance of the country. Therefore, the above mentioned economic theory also explains that between CPI, Exchange Rate and Trade Balance should be a positive dependency, if the euro becomes more expensive, in an economy where imports of consumer goods are important, goods and services are expected to become more expensive, so the CPI will increase . Moreover, the trade 
balance in favor of imports deepened, especially for consumer goods is expected to increase in the CPI, hence inflation. In this case we can speak of a kind of "import" of inflation, especially when the prices of these goods out grow. In this way the growth of imports may not only be due to increased physical volume of imports but also of their value due to higher prices of imports.

But these reports have not been tested or evaluated for the Albanian economy, so here is a related problem of not recognising these effects on economy.

\section{Objectives}

In this research we have the following objectives:

i. Empirical assessment of the impact of the euro exchange rate on the level of the INDEX Consumer Price Index (CPI)

ii. Empirical assessment of the impact on the trade balance level INDEX Consumer Price Index (CPI)

iii. Empirical assessment of the impact of the euro exchange rate on the trade balance level

iv. Build one or several alternative models for short-term prognosis exchange rate and CPI

\section{Methodology and data}

The methodology we used in this research is the statistical and econometric modeling, mainly:

a. Regression models multisectorial

b. Hammering double exponential constant (mainly Holt-Winter)

c. ARIMA models

The data we have received from the site of the Bank of Albania. They are time series with monthly terms, starting from 2007 until the end of 2011. Before 2007 there is no data for the three variables simultaneously, so we are limited in the time period where no data for the three variables.

Variables for which we have data received three, as mentioned in the above discussion of the problem:

- Exchange rate of the euro expressed in lek lek for one euro, February Course

- The trade balance in euros, expressed as the difference between exports with imports, February Balance

- Consumer Price Index, expressed in\%, February CPI.

\section{The research results}

\subsection{Trends and Indicators}

The data show that the exchange rate (the euro) has a positive dynamics, as shown in Chart 1 below:

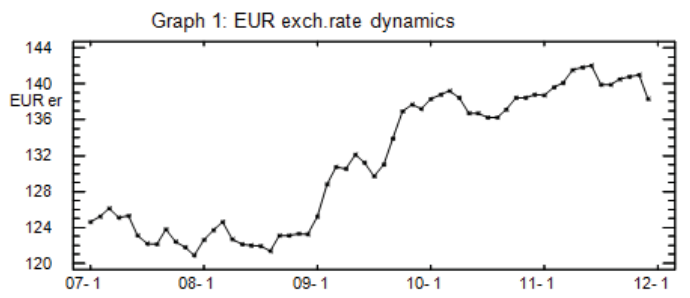

But the course dynamics is characterized by seasonal light shaking. Below we present quarterly seasonal indices of course, where the positive effects appear in the second season and the third:

Table 1: Seasonal Indices of the Exchange Rate EUR

\begin{tabular}{|c|c|c|c|c|}
\hline Tremujori & 1 & 2 & 3 & 4 \\
\hline Index & 100,109 & 100,247 & 100,016 & 99,6271 \\
\hline
\end{tabular}

A similar dynamics is also presented in CPI (Graphic 2): 


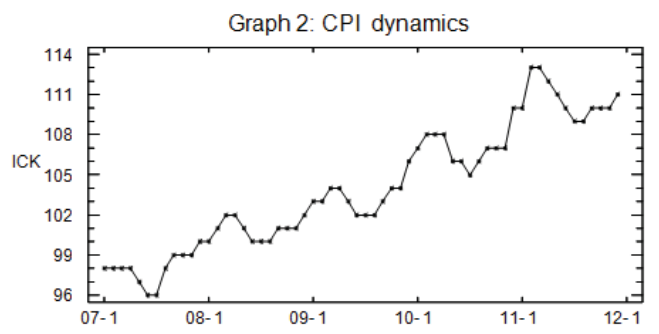

The CPI dynamics has seasonal indexes:

Table 2: Seasonal Indexes of CPI

\begin{tabular}{|c|c|c|c|c|}
\hline Quarter & 1 & 2 & 3 & 4 \\
\hline Index & 100,061 & 99,9673 & 99,7768 & 100,195 \\
\hline
\end{tabular}

As the dynamics of the trade balance is as follows:

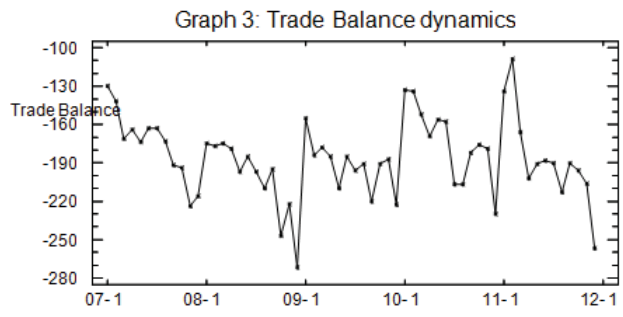

\subsection{Empirical Dependence}

When viewed alone, it appears that the trade balance does not depend significantly on the exchange rate:

Table 3: Bilance's dependency from the exchange rate

\begin{tabular}{|l|c|c|c|c|}
\hline Variable & Coefficient & Standard Error & $\mathrm{t}$ & Prob. \\
\hline $\mathrm{C}$ & -255.7995 & 69.07561 & -3.703180 & 0.0005 \\
\hline RATE & 3.329549 & 3.113914 & 1.069249 & 0.2895 \\
\hline RATE(-1) & -2.811532 & 3.115805 & -0.902345 & 0.3707 \\
\hline $\mathrm{R}$ & 0.033792 & Avg. Var. Corr & -187.0678 \\
\hline Ajusted Ri & -0.000716 & St. Err.Var. Corr & 29.82874 \\
\hline Regress SE & 29.83942 & Akaike chriteria & 9.679047 \\
\hline SHCM & 49861.88 & Shvarc chriteria & 9.784684 \\
\hline Log likelihood & -282.5319 & Stat. F & 0.979260 \\
\hline Stat. d & 1.223021 & Prob(Stat. F) & 0.381927 \\
\hline
\end{tabular}

We identify the balance does not depend on the exchange rate significantly, although note that the growth rate has a tendency to balance grow!.

Table 4: CPI dependence of foreign exchange and / or trade balance

\begin{tabular}{|l|c|c|c|c|}
\hline Variable & Coeficient & Standard Error. & $\mathrm{t}$ & Prob. \\
\hline C & 29.64717 & 4.443233 & 6.672432 & 0.0000 \\
\hline RATE & 0.566246 & 0.033784 & 16.76061 & 0.0000 \\
\hline R & 0.828867 & Mes. Var. Varur & 104.0000 \\
\hline
\end{tabular}




\begin{tabular}{|l|c|l|l|}
\hline Ajusted Ri & 0.825917 & Gab.St. Var. Varur & 4.650497 \\
\hline Regress SE & 1.940341 & Akaike chriteria & 4.196370 \\
\hline SHKM & 218.3656 & Shwarc chriteria & 4.266181 \\
\hline Log likelihood & -123.8911 & Stat. F & 280.9179 \\
\hline Stat. d & 0.280060 & Prob(Stat. F) & 0.000000 \\
\hline
\end{tabular}

CPI statistically depends on the exchange rate, the rate increased by $1 \mathrm{ALL} C P I$ is expected to rise by $0.55 \%$, but the error term is autokorrelacion first order of important. (See table below):

Table 5: Correlations for the error term

\begin{tabular}{|c|c|c|c|c|c|c|}
\hline Autocorrelatic & Parcial Correlation & & $A C$ & PAC & Stat-Q & Prob \\
\hline$.||^{\star \star \star \star \star \star ~} \mid$ &.||$^{\star \star \star \star \star \star \star ~}$ & 1 & 0.828 & 0.828 & 43.195 & 0.000 \\
\hline 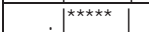 & 1. & 2 & 0.675 & -0.031 & 72.450 & 0.000 \\
\hline$f^{\star \star \star \star \star}$ & $\star^{*}$. & 3 & 0.513 & -0.119 & 89.638 & 0.000 \\
\hline 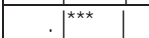 &.$* 1$. & 4 & 0.365 & -0.065 & 98.492 & 0.000 \\
\hline $1^{\star \star}$ & ${ }^{*}{ }^{*}$ & 5 & 0.213 & -0.118 & 101.55 & 0.000 \\
\hline.$\left.\right|^{*}$. & .1. & 6 & 0.104 & 0.016 & 102.30 & 0.000 \\
\hline
\end{tabular}

$\mathrm{CPI}$ depends on the course without delay, about the same as from the course with a delay, but the course is too late kolinear with a course without delay and need not be kept in the model.

To eliminate the effect of the first order autocorrelation in the series back and CPI Course in stationary chain through differentiation, after which we assess:

Table 6: Dependence chain CPI differences on exchange rate difference

\begin{tabular}{|l|c|c|c|c|}
\hline \multicolumn{5}{|c|}{ Variable corr: D(IÇK) } \\
\hline Variable & Coefficient & Standard Error & t & Prob. \\
\hline C & 0.169136 & 0.123568 & 1.368769 & 0.1764 \\
\hline D(RATE) & 0.220509 & 0.097069 & 2.271669 & 0.0269 \\
\hline R & 0.083019 & Avg. Var. Corr & 0.220339 \\
\hline Ajusted Ri & 0.066931 & St. Err.Var. Corr & 0.966112 \\
\hline Regress SE & 0.933220 & Akaik Criteria & 2.732960 \\
\hline SHKM & 49.64133 & Shwarc Criteria & 2.803385 \\
\hline Log likelihood & -78.62232 & Hannan-Quinn Criteria & 2.760451 \\
\hline Stat. F & 5.160482 & Stat. d & 1.719545 \\
\hline Prob(Stat. F) & 0.026899 & \multicolumn{3}{|}{} \\
\hline
\end{tabular}

We notice that the difference in the exchange rate affects significantly increase in the difference of the CPI increase.

Table 7: Dependence of the rate of $\mathrm{CPI}$, as well as a dynamic exchange with delay

\begin{tabular}{|l|c|c|c|c|}
\hline \multicolumn{5}{|c|}{ Variabli corr: IÇK } \\
\hline Variable & Coefficient & Standard Error & t & Prob. \\
\hline C & 30.14623 & 4.511657 & 6.681853 & 0.0000 \\
\hline Rate & 0.478304 & 0.203385 & 2.351722 & 0.0222 \\
\hline Rate(-1) & 0.084578 & 0.203508 & 0.415601 & 0.6793 \\
\hline R & 0.828374 & Avg. Var. Corr & 104.1017 \\
\hline Ajusted Ri & 0.822244 & St. Err.Var. Corr & 4.622639 \\
\hline Regres SE & 1.948954 & Akaik Criteria & 4.221972 \\
\hline SHKM & 212.7117 & Shwarc Criteria & 4.327610 \\
\hline Log likelihood & -121.5482 & Stat. F & 135.1453 \\
\hline Stat. d & 0.270781 & Prob(Stat. F) & 0.000000 \\
\hline
\end{tabular}

Finally, we note that in our country the exchange rate change is reflected in the change of the CPI, CPI therefore 
depends on the course, but since the error term is high autocorrelation coefficient of the first order, the terms may include an AR (1) in the model. In this case there is a major upgrade of the model, because the coefficient of determination ranges from 0.828 to 0.96 . This model can be used for prognosis:

Table 8: Model AR(1) for the rate

\begin{tabular}{|l|c|c|c|c|}
\hline \multicolumn{5}{|c|}{ Variable corr: IÇK } \\
\hline Variable & Coefficient & Standard Error & $\mathrm{t}$ & Prob. \\
\hline C & 76.76177 & 15.70501 & 4.887725 & 0.0000 \\
\hline Rate & 0.240204 & 0.098887 & 2.429069 & 0.0184 \\
\hline AR(1) & 0.962537 & 0.041179 & 23.37438 & 0.0000 \\
\hline R & 0.960530 & Avg. Var. Corr & 104.1017 \\
\hline Ajusted Ri & 0.959120 & St. Err.Var. Corr & 4.622639 \\
\hline Regres SE & 0.934641 & Akaike Criteria & 2.752201 \\
\hline SHCM & 48.91905 & Shwarc Criteria & 2.857839 \\
\hline Log likelihood & -78.18994 & Stat. F & 681.3948 \\
\hline Stat. d & 1.695406 & Prob(Stat. F) & 0.000000 \\
\hline
\end{tabular}

Another model, competitive with the first, would be as follows:

Table 9: An alternative autoregression model for the Course

\begin{tabular}{|l|c|c|c|c|}
\hline \multicolumn{5}{|c|}{ Variabli i varur: KURSI } \\
\hline Variabli & Coefficient & Standard Error & $\mathrm{t}$ & Prob. \\
\hline C & 2.295871 & 2.971653 & 0.772590 & 0.4432 \\
\hline Rate (-1) & 1.324907 & 0.143251 & 9.248853 & 0.0000 \\
\hline Rate $(-2)$ & -0.447166 & 0.230150 & -1.942935 & 0.0573 \\
\hline Rate $(-3)$ & 0.105926 & 0.144472 & 0.733196 & 0.4667 \\
\hline R & 0.974065 & Avg. Var. Corr & 131.6246 \\
\hline Ajusted Ri & 0.972597 & St. Err.Var. Corr & 7.539687 \\
\hline Regress SE & 1.248103 & Akaike Criteria & 3.348718 \\
\hline SHCM & 82.56135 & Shvarc Criteria & 3.492090 \\
\hline Log likelihood & -91.43847 & Stat. F & 663.5301 \\
\hline Stat. d & 1.906086 & Prob(Stat. F) & 0.000000 \\
\hline
\end{tabular}

The exchange rate depends on the dynamic delay of up to two, in other words, the exchange is a process AR (2), this model can be used for prognosis of CPI. CPI depends on the course, but to a large extent and also the trade balance (Table 10).

$\mathrm{CPI}$ model with two variables supports the analysis by means of indicators $\mathrm{Cp}$ (Mallou), as follows. Model with two variables has little $\mathrm{Cp}$ with the two models with only one of the variables. The model with the two variables has the highest coefficient of determination adjusted (Table 11).

Table 10: Dependence of the rate of $\mathrm{CPI}$ and trade balance

\begin{tabular}{|l|c|c|c|c|}
\hline \multicolumn{5}{|c|}{ Veariable Corr: CPI } \\
\hline Variable & Coefficient & Standard Error & t & Prob. \\
\hline C & 26.60175 & 4.830357 & 5.507202 & 0.0000 \\
\hline BALANCE & -0.012515 & 0.008244 & -1.518098 & 0.1345 \\
\hline RATE & 0.571701 & 0.033603 & 17.01322 & 0.0000 \\
\hline R & 0.835517 & Avg. Var. Corr & 104.0000 \\
\hline Ajusted Ri & 0.829746 & St. Err.Var. Corr & 4.650497 \\
\hline Regres SE & 1.918880 & Akaike Criteria & 4.190067 \\
\hline SHCM & 209.8797 & Shvarc Criteria & 4.294784 \\
\hline Log likelihood & -122.7020 & Stat. F & 144.7707 \\
\hline Stat. d & 0.319577 & Prob(Stat. F) & 0.000000 \\
\hline
\end{tabular}


Table 11: Cpi and the Ajusted Coeficient

\begin{tabular}{|c|c|c|c|c|}
\hline \multirow{2}{*}{$\begin{array}{c}\text { Standard Average } \\
\text { mistake }\end{array}$} & \multicolumn{2}{|c|}{ Ajusted $\mathrm{R}^{2}$} & \multirow[b]{2}{*}{$\mathrm{Cp}$} & \multirow{2}{*}{$\begin{array}{l}\text { Included } \\
\text { variables }\end{array}$} \\
\hline & $\mathbf{R}^{2}$ & $\mathbf{R}^{2}$ & & \\
\hline 3,6821 & 83,5517 & 82,9746 & 3,0 & $\mathrm{AB}^{1}$ \\
\hline 3,76492 & 82,8867 & 82,5917 & 3,30462 & $\mathrm{~A}$ \\
\hline 21,6271 & 1,69492 & 0,0 & 290,45 & $B$ \\
\hline
\end{tabular}

But this model suffers from autocorrelation in the error term and we will preffer CPI model with only the exchange rate.

\section{Prognosis exchange rate}

In the short-term prognosis are excercised with exponential flattening method of Holt. This model is compared with a number of other models and statistical indicators (standard error) better than almost everyone else. Only one of them is somewhat smaller (see below) but Holt model takes into account seasonal fluctuations in prognosis, so we preferred this model.

$\checkmark$ Holt model with two constants: 0.9999 and 0.0344 , with error 1:23

$\checkmark$ linear model: rate $=-149552+0393 * t$, with error 3:08

$\checkmark$ flattening model with a simple exponential constant 0.9999 , with error 1223

$\checkmark$ flattening exponential model with constant linear Brown 0.7878, with error 1295

$\checkmark$ flattening exponential model with three constant sheshuese Brown $0.868,0.0001,0.0517$, with error 1361 .

Prognosis for the 12 months of 2012 with the Holt model is as following table:

Table 12: Course prognosis model of Holt

\begin{tabular}{|c|c|c|c|}
\hline Period & Foracast & $\begin{array}{c}\text { Left limit of the } \\
\text { prognosis }\end{array}$ & $\begin{array}{c}\text { Right limit of the } \\
\text { prognosis }\end{array}$ \\
\hline $12-1$ & 139,132 & 136,820 & 141,444 \\
\hline $12-2$ & 139,486 & 136,156 & 142,816 \\
\hline $12-3$ & 139,326 & 135,187 & 143,465 \\
\hline $12-4$ & 138,946 & 134,105 & 143,787 \\
\hline $12-5$ & 139,781 & 134,251 & 145,310 \\
\hline $12-6$ & 140,136 & 133,970 & 146,302 \\
\hline $12-7$ & 139,974 & 133,221 & 146,727 \\
\hline $12-8$ & 139,592 & 132,284 & 146,899 \\
\hline $12-9$ & 140,430 & 132,518 & 148,342 \\
\hline $12-10$ & 140,786 & 132,303 & 149,268 \\
\hline $12-11$ & 140,623 & 131,608 & 149,637 \\
\hline $12-12$ & 140,237 & 130,715 & 149,760 \\
\hline
\end{tabular}

The latest data on the Balance of Payments for 2012 show a net current account deficit of EUR 671,1 million at the end of Third Quarter (Q3). This is estimated as 9,2\% of nominal GDP. Trade balance amounted a deficit of EUR 1,481 million with the main indicators given in the table.

Table 13: Albania's BoP: Trade Balance

Current Acct (EUR mIn)
Change YOY
CA / GDP
Trade Balance
$\quad$ exp fob
imp fob

$\begin{array}{cc}9 \mathrm{M} \mathrm{2011} & \frac{9 \mathrm{M} \mathrm{2012}}{--671.1} \\ -169.1 & -12.80 \% \\ 11.10 \% & 9.20 \% \\ -1.583 & -1.4814 \\ 1.045 & 1.122 \\ -2.628 & -2.603\end{array}$

Source: Bank of Albania

${ }^{1} \mathrm{~A}=$ Rate, $\mathrm{B}=$ Balance 
The level of economic activity during 2012 was slowed down with its impact at main indicators considered in this study. However the exchange rate was pretty stable with annual CPI level of 2,4\%.

According to the declarations of the Bank of Albania, the inflation rate increased progressively during first three quarters of 2012, and fell at the end of the year.

The exchange rate EUR/ALL was almost at the limits foreseen at the prognosis of the Holt model as shown in the annual data graph:

Source: Bank of Albania

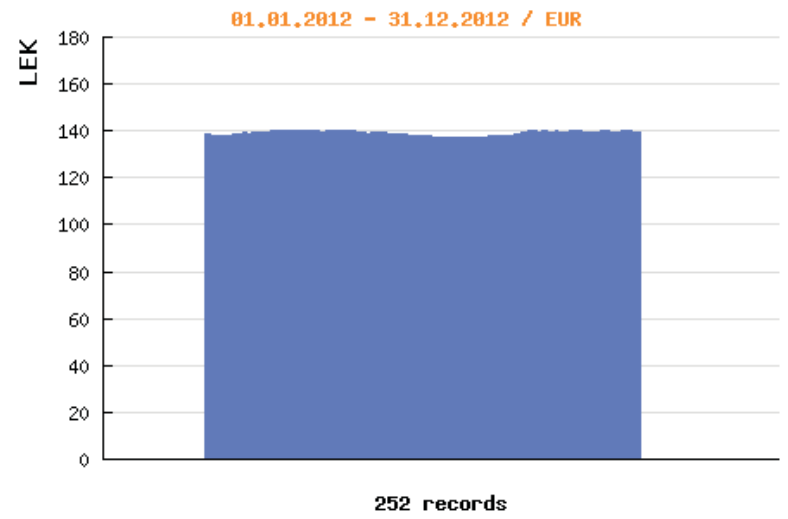

\section{Key Conclusions and Recommendations}

The indicators used in our model are predicting the trends and relations among exchange rate, CPI and trade balance, although the data series are limited.

Some of the main conclusions drawn from the above analysis are:

a. The level of consumer prices in Albania significantly affected by the exchange rate of the euro. This is due to the large share of consumer goods occupy our imports.

b. Trade balance, contrary to what is expected on theoretical grounds, fails to significantly influence the way that the exchange rate. This may perhaps because competition in our economy is not yet fully in regional trade and beyond. This would require more in-depth studies to clarify.

c. Consumer price level depends to some extent, though not so significant, the trade balance. This can be explained by the fact that our trade balance is very negative, and price changes in the global arena transferred through imports in the level of consumer prices in the country in what is known as imported inflation.

Some of the main recommendations are:

a) Monitoring and surveillance of exchange rate can be a tool to keep under control the acceptable level of consumer prices, and maybe should be used especially when fluctuations (humiliating) sensitive to our currency.

b) To assess the relative role of the exchange rate on the trade balance, we would recommend a thorough study and evaluation of factors affecting the level of trade balance, as well as an analysis of how competition works in foreign trade.

c) Also analysis, could split and take into consideration the main important groups of CPI basket and main contributors on Albania's trade balance. These might give more clarifications and prove stronger linkages on the factors considered in this approach.

\section{References}

Banka e Shqipërisë : Buletini Statistikor, 2005, 2006, 2007, 2008, 2009, 2010, 2011, 2012

IMF: Exchange Rate Assessments: CGER Methodologies, Occasional paper 261,Washington DC. 2008

M.Osmani: Ekonometri, Tiranë, 2010

M.Osmani: Statistikë, Tiranë, 2011

Monetary policy report of BOA Q4 2012 